\title{
LA BABel SUbVertida
}

\section{Mtro. Felipe Garrido*}

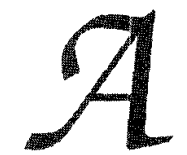

ntes que nada, quiero agradecer al director del Centro de Enseñanza para Extranjeros de la Universidad Nacional Autónoma de México, al doctor Guillermo Pulido, que me haya invitado a participar en esta ocasión tan especial. Con esta ceremonia, simbólicamente se devela ante la comunidad del CEPE, ante la comunidad de la UNAM, la escultura Resonancia y movilidad del pensamiento, obra de María Eugenia Gamiño Cruz. Tener la oportunidad de dirigirles la palabra en estas circunstancias es un alto honor que mucho agradezco.

Si esta escultura nos remite al lenguaje, he de insistir en que estamos hechos de ideas y creencias: nuestros conocimientos y leyes, nuestros proyectos y memorias, nuestras fabulaciones son palabras, ya puestas en el habla, ya puestas por escrito. Pensamos un universo, experimentamos sensaciones y sentimientos, concebimos ideas y ficciones, recordamos el pasado y proyectamos el futuro nombrando certezas y posibilidades que antes han sido conformadas por nuestro lenguaje.

Y de esta convicción, fatalmente he de pasar a una confesión íntima, profundamente personal. Debo decirles que de las muchas pesadillas que noche a noche espantaron mi infancia, ninguna fue peor que "El ascenso a la torre", como yo la llamaba. Me veía en una oscura tarde de tormenta, al borde de un precipicio, en un sendero que flaqueaba una inabarcable, enorme pirámide cónica, alta como una montaña; subía o bajaba yo casi a gatas, arrimándome al muro, resbalando, cegado por la lluvia, vislumbrando a la luz de los relámpagos: un cuadro horrible que se extendía hasta donde llegaba mi vista, centenares de metros por debajo de mis pies.
Hombres y mujeres semidesnudos hormigueaban por la torre, abandonándola; divididos en pequeñas bandas, combatían a muerte y huían por el campo, cubiertos de odio y terror, cargando bultos, ropa, muebles, algún niño trabajosamente sostenido, algún animal.

Al despertar, entre gritos, recordaba dónde había quedado, en la mesa del comedor, entre mis libros de segundo o tercero de primaria, forrados todos con la tela azul que la escuela pedía 0 mamá acostumbraba, mi texto de historia sagrada. Recordaba la página exacta, la ubicación precisa donde se reproducía el trabajo de algún aprendiz de Durero y del Bosco que presentaba, con pudoroso realismo, la torre de mi sueño. El grabado tenía una leyenda, "La confusión de la lenguas", que provocaba mi propia confusión. ¿Con qué, por quién eran o habían sido confundidas cuáles lenguas? ¿Qué tenían que ver con el lenguaje aquellos seres frenéticos? Debieron pasar varios años antes de que pudiera conocer, más o menos de primera mano, el origen de aquella historia que cuentan "La Epopeya de Gilgamesh" y más tarde "El Génesis":

Yahvé bajo para ver la ciudad $y$ la torre que los hombres estaban levantando, y dijo Yahvé: "Veo que todos forman un solo pueblo y tiene una misma lengua. Si esto sigue adelante, nada les impedirá que consigan todo lo que se propongan. Bajemos pues, $y$ confundamos su lengua, de modo que no se entiendan los unos con los toros"

Así, Yahvé los dispersó sobre la superficie de la tierra, $y$ dejaron de construir la ciudad. Por eso se llamó Babel, porque allí Yahvé confundió el lenguaje de todos los habitantes de la tierra, $y$ desde allí los dispersó Yahvé por toda la tierra.

* Catedrático del CEPE, Director General de Publicaciones de ConaculTA 


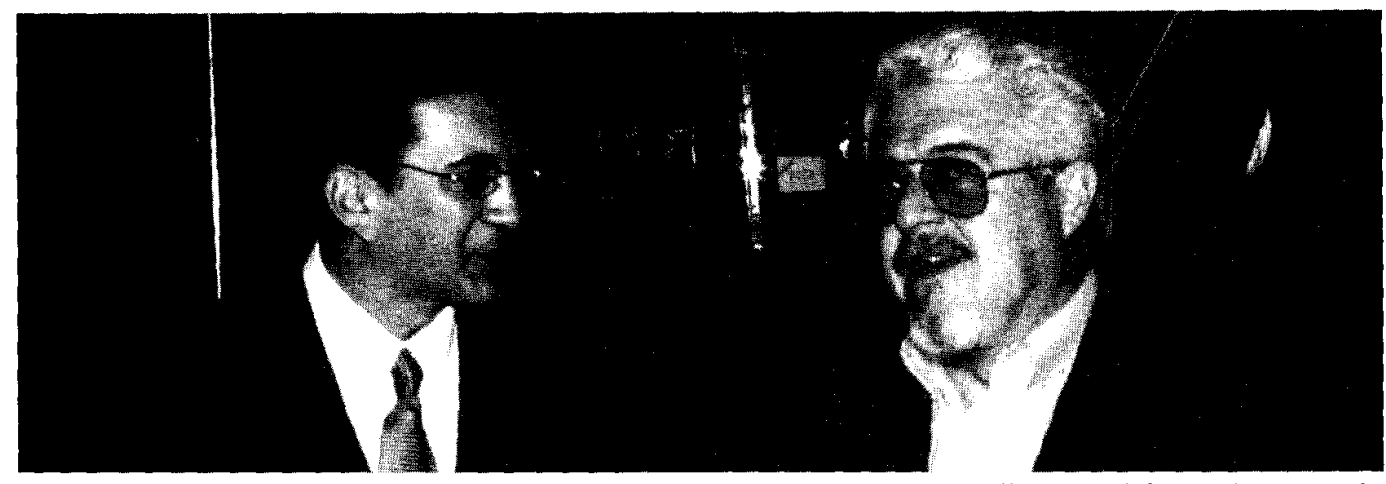

Guillermo Pulido y Felipe Garrido

Fue preciso que pasara mucho tiempo más todavía, antes de que yo pudiera advertir los alcances terribles de Babel. Ahora sé que la maldición divina no se reduce a quienes hablan lenguas diversas; incluye a los hablantes de una misma lengua. De pronto queda al descubierto la probable filiación bíblica de las teorías de Maurice Blanchot y los demás autores de su escuela, quienes sostienen que es imposible comunicarse por medio del lenguaje. Con esta óptica, lo más sorprendente no es que existan innumerables lenguas, sino que cada uno de los seres humanos posea su propia lectura del mundo y de la vida, su propia conciencia, armada a partir de la capacidad para nombrar su experiencia. De acuerdo con esto, las palabras que ahora voy pronunciando no tienen el mismo significado para ninguno de nosotros. A final de cuentas, lo que dice el mito de Babel es lo mismo que sostiene esa corriente de la lingüística moderna: cada hablante se encuentra encarcelado en su propio ideolecto.

No debe extrañarnos que, desde aquel mismo momento en que los hombres supieron que los separa aun la lengua propia, comenzaran a esforzarse para romper esa barrera. Lo más característicamente humano es el impulso de ser como dioses: saberlo todo, poderlo todo, conocerlo todo, conservarlo todo, vivir por siempre. Vista de esta manera, la función primordial del lenguaje no sería la comunicación, sino la expresión. Hablamos y escribimos antes que nada para manifestarnos, para salir de nosotros mismos; sólo después surge el impulso de tender puentes hacia los demás.

En una obra que es un clásico de nuestro tiempo. Después de Babel, George Steiner dice que la proliferación de lenguas mutuamente incomprensibles nace de un impulso fundamental del lenguaje; que los lenguajes buscan de manera natural su propia forma y que eso los hace diversos. Que comunicar información, hechos manifiestos y verificables, constituye sólo una parte "y quizás una parte secundaria" el discurso humano. Que los orígenes y la naturaleza del habla incluyen su capacidad de invención.

A pesar de todo, hay una evidencia empírica de que nuestros esfuerzos por comunicarnos no son estériles. Basta los trabajos del Centro de Enseñanza para Extranjeros, de sus alumnos y sus maestros, para comprobar que es posible avanzar hacia un sólido entendimiento no sólo entre hablantes de lenguas diversas, sino aun entre hablantes de la misma lengua. Y esta esperanza se apoya incluso en la opinión de los eruditos. Frente a Blanchot y sus partidarios, otros autores, como Reyes, Bloomfield y Richards, sostienen que el lenguaje es un intento colectivo de reducir al mínimo las diferencias que por fuerza existen entre los significantes $y$ entre las significaciones que utiliza cada hablante.

Podemos concluir, quizá, que la comunicación es siempre parcial, pero es obvio que alcanza 
un nivel suficiente para que, por ejemplo, podamos estar ahora aquí, intercambiando enunciados lingüísticos, espero que con algún provecho. Podemos concluir, también, que el más rudimentario acto de comunicación, aun en la lengua $y$ en el tiempo propios, lleva implícita una tarea de traducción; es decir, la de construir una segunda obra, en la lengua meta, paralela de la que ofrece el emisor, en la cual se conserven el sentido, la información y la intención del original.

Para anular la maldición de Babel, para llegar a la armonía de esa forma esférica que ofrece la escultura de María Eugenia, no basta, por supuesto, compartir una lengua. Hace falta hacerse uno, identificarse con el otro; hace falta acompasar los corazones $y$ las voluntades; sustituir el recelo con la confianza $y$ trabajar con un mismo propósito; hace falta levantar una misma torre.

Al consagrarse a difundir la lengua, la historia y la cultura de México; al

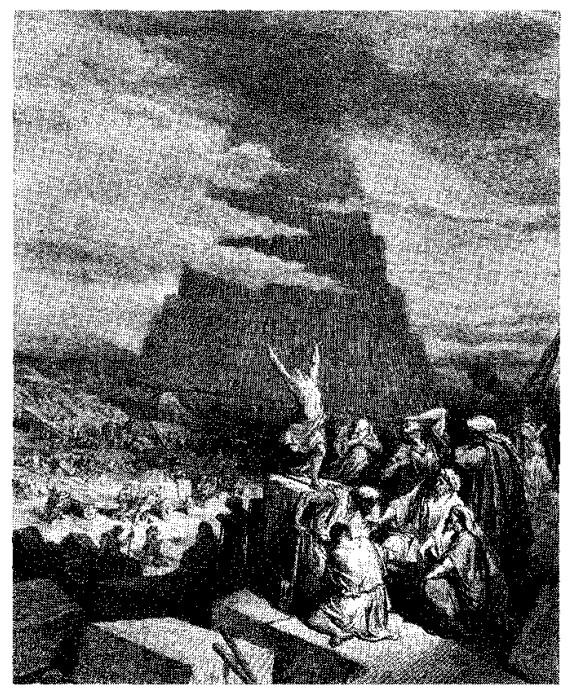

Torre de Babel por Gustav Doré poetas. Horrorizado por el horror de la guerra, por "la mutilación de la metralla", por los "negros y aciagos mapas" grabados por la fusilería "en la cal/ de todas las paredes/ de la aldea espectral", López Velarde llamó a su pueblo "El Edén subvertido", es decir, el paraíso trastornado. En nuestro mundo en guerra, en nuestras ciudades en guerra, en nuestra sociedad que tan lejos está de haber anulado esas espantosas formas de violencia que son la pobreza, la enfermedad, el hambre y la ignorancia, bien podemos ahora fijarnos el propósito de subvertir a Babel.

Para manifestar nuestra decisión, podríamos formar una ronda ideal en derredor de esta escultura. No solamente nosotros, sino todos quienes por aquí han pasado, en una gran asamblea, no de sombras sino de presencias vivas. Cito una nómina mínima que asalta la memoria: Vasconcelos y Henríquez Ureña; Torri y Soledad Anaya Solórzano; Pellicer, Caso y Torres Bodet; Cosío Villegas, recibir en México a gente llegada de todos los rumbos que marca la Rosa del Viento, a gente dispuesta a intentar la mutua traducción de palabras y de voluntades; al extender esta intención a San Antonio, a Taxco, a Hull, a Chicago, el Centro de Enseñanza para Extranjeros de nuestra Universidad Nacional ha contribuido esforzadamente a construir un mundo donde sea posible una convivencia mejor. Un mundo donde no haya lugar para mi pesadilla infantil.

Todo esto comenzó hace ochenta años, en julio de 1921, cuando inició sus labores la Escuela de Verano; un mes antes, el 19 de Junio, murió aquí, en esta Ciudad de México, Ramón López Velarde, uno de nuestros en verdad grandes
León Felipe y Julio Jiménez Rueda; Abreu Gómez, Novo, Usigli y Villaurrutia; Gorostiza y Rodríguez Lozano; Justino Fernández, Edmundo O' Gorman y María del Carmen Millán; Francisco de la Maza y Vicente T. Mendoza; Monterde, Azuela y Castro Leal; si tomados de las manos quisiéramos bailar, bien podría marcar el paso, con su gracia de siempre, Alura Flores. A la sombra, al amparo de la palabra y el arte de quienes nos han antecedido, con nuestro trabajo, podremos un día sentir que hemos llegado al punto en que sea realidad, en su más alta expresión, el lema de nuestra casa: "Por mi raza (por la raza de los hombres y las mujeres del mundo) hablará el espíritu" 